\title{
Prevalence and distribution of G6PD deficiency: implication for the use of primaquine in malaria treatment in Ethiopia
}

Eugenia Lo ${ }^{1 *+} \oplus$, Daibin Zhong ${ }^{2 \dagger}$, Beka Raya ${ }^{3}$, Kareen Pestana', Cristian Koepfli', Ming-Chieh Lee², Delenasaw Yewhalaw ${ }^{3,5}$ and Guiyun Yan ${ }^{2^{*}}$

\begin{abstract}
Background: G6PD enzyme deficiency is a common enzymatic X-linked disorder. Deficiency of the G6PD enzyme can cause free radical-mediated oxidative damage to red blood cells, leading to premature haemolysis. Treatment of Plasmodium vivax malaria with primaquine poses a potential risk of mild to severe acute haemolytic anaemia in G6PD deficient people. In this study, the prevalence and distribution of G6PD mutations were investigated across broad areas of Ethiopia, and tested the association between G6PD genotype and phenotype with the goal to provide additional information relevant to the use of primaquine in malaria treatment.
\end{abstract}

Methods: This study examined G6PD mutations in exons 3-11 for 344 febrile patient samples collected from seven sites across Ethiopia. In addition, the G6PD enzyme level of 400 febrile patient samples from Southwestern Ethiopia was determined by the CareStart ${ }^{\mathrm{TM}}$ biosensor. The association between G6PD phenotype and genotype was examined by Fisher exact test on a subset of 184 samples.

Results: Mutations were observed at three positions of the G6PD gene. The most common G6PD mutation across all sites was A376G, which was detected in 21 of 344 (6.1\%) febrile patients. Thirteen of them were homozygous and eight were heterozygous for this mutation. The G267+119C/T mutation was found in 4 (1.2\%) individuals in South Ethiopia, but absent in other sites. The G1116A mutation was also found in 4 (1.2\%) individuals from East and South Ethiopia. For the 400 samples in the south, 17 (4.25\%) were shown to be G6PD-deficient. G6PD enzyme level was not significantly different by age or gender. Among a subset of 202 febrile patients who were diagnosed with malaria, 11 (5.45\%) were G6PD-deficient. These 11 infected samples were diagnosed with Plasmodium vivax by microscopy. Parasitaemia was not significantly different between the G6PD-deficient and G6PD-normal infections.

Conclusions: The prevalence of G6PD deficiency is modest among febrile patients in Ethiopia. G6PD deficiency testing is thus recommended before administrating primaquine for radical cure of $P$. vivax infected patients. The present study did not indicate a significant association between G6PD gene mutations and enzyme levels.

Keywords: G6PD deficiency, Malaria, Plasmodium vivax, Primaquine, Genotype-phenotype, Ethiopia

\footnotetext{
*Correspondence: eugenia.lo@uncc.edu; guiyuny@uci.edu

${ }^{\dagger}$ Eugenia Lo and Daibin Zhong are co-first authors of equal contribution

${ }^{1}$ Biological Sciences, University of North Carolina at Charlotte, Charlotte,

NC 28223, USA

2 Program in Public Health, College of Health Sciences, University

of California, Irvine, CA 92697, USA

Full list of author information is available at the end of the article
}

(c) The Author(s) 2019. This article is distributed under the terms of the Creative Commons Attribution 4.0 International License (http://creativecommons.org/licenses/by/4.0/), which permits unrestricted use, distribution, and reproduction in any medium, provided you give appropriate credit to the original author(s) and the source, provide a link to the Creative Commons license, and indicate if changes were made. The Creative Commons Public Domain Dedication waiver (http://creativecommons.org/ publicdomain/zero/1.0/) applies to the data made available in this article, unless otherwise stated. 


\section{Background}

Glucose-6-phosphate dehydrogenase (G6PD) is an enzyme involved in the pentose monophosphate pathway. Deficiency of this enzyme leads to free radical-mediated oxidative damage to red blood cells, and in turn causes haemolysis. G6PD deficiency is the most common enzymatic disorder of red blood cells, affecting 400 million people worldwide [1]. It is an X-linked disorder with high prevalence particularly in people of African, Asian, and Mediterranean descent [1]. In Africa, the most common G6PD enzyme-deficient variant is A- [2]. Females with G6PD A- heterozygotes have been shown with selective advantage against severe malaria [3-5]. By selection, this G6PD-deficient trait becomes prevalent $(8 \%)$ in populations where malaria is endemic [6].

The prevalence of G6PD deficiency is highly relevant to the choice of drug used in anti-malarial treatment [7, 8]. A number of drugs, such as primaquine, dapsone, sulfonamides, quinolones, chloramphenicol, nitrofurantoins (antibiotics), and phenazopyridine (analgesics), have been described as haemolytic trigger that causes haemolytic crisis in G6PD-deficient individuals [9, 10]. Primaquine is the recommended treatment drug to eliminate Plasmodium vivax hypnozoites and Plasmodium falciparum gametocytes, along with the goal to progress towards zero malaria transmission in Africa [11-14]. It is an ideal agent to be used as primary prophylaxis against $P$. vivax [6]. However, primaquine can also induce oxidative stress causing a spectrum of haemolytic anaemia ranging from mild to severe haemolysis in G6PD-deficient individuals [15]. The likelihood of developing haemolysis and its severity depends on the level of enzyme deficiency, which in turn is determined by the type of G6PD variant [16-18]. The risk for haemolytic anaemia is particularly high in patients who are treated for $P$. vivax malaria because they are usually given a higher dose of primaquine (0.25-0.5 $\mathrm{mg}$ in a 14-day treatment regime) compared to those treated for $P$. falciparum (a single dose of $0.25 \mathrm{mg}$ on the first day of treatment) [19]. A high dose of primaquine ( $0.5 \mathrm{mg}$ base $/ \mathrm{kg}$ daily for 14 days) has been previously shown to be more effective than a low dose (0.25 $\mathrm{mg}$ base $/ \mathrm{kg}$ daily for 14 days) in eliminating primary blood infection and preventing relapse episodes in $P$. vivax patients $[11,20-22]$. However, the lack of G6PD level information, inaccurate methods of screening G6PD deficiency, and the uncertainty in the safety of a single versus long-term primaquine dosage pose risk to malaria patients when treat with primaquine.

The gene encoding the G6PD protein consists of 13 exons and 12 introns [23] and is located on the X chromosome. This gene is highly polymorphic with nearly 160 mutations at the DNA level that are potentially associated with G6PD deficiency [24]. The frequency of these mutations varies among populations and countries. For instance, mutation S188F, sometimes called the Mediterranean mutation, is most prevalent among individuals from the Middle East [25]. Mutations C131G and G487A that were common in Dhaka, Bangladesh appear to be linked to G6PD deficiency by affecting NADP binding or disrupting the protein structure [26]. The G6PD genetic variants were relatively homogeneous in America, Africa, and western Asia compared to those in East Asia and Oceania. In North America, Africa, Yemen and Saudi Arabia, G6PD*A- variant is predominant among populations. By contrast, G6PD variants are highly heterogeneous in East Asia such as China and the Asia-Pacific where no single variant predominates $[6,27]$.

Ethiopia is one of the few African countries where $P$. vivax and $P$. falciparum coexist, and account for $60 \%$ and $40 \%$ of the malaria cases, respectively [28]. G6PD deficiency was previously estimated to be as high as $17 \%$ in southwestern Ethiopia based on the CareStart ${ }^{\mathrm{TM}}$ fluorescence spot test [29]. The mutation A376G that constitutes G6PD*A- variant accounted for nearly $23 \%$ of the malaria patients. Other mutations including rs782669677 (535 G->A), rs370658483 (485+37 G->T), and chrX:154535443 (C->T) were recently observed in the same geographical region through an investigation of a short segment of the G6PD gene [30]. These mutations did not appear to disrupt function or structure of the G6PD protein [30]. In this study, the prevalence and distribution of G6PD mutations were investigated among a large number of febrile patients across broad areas of Ethiopia. For a subset of samples, the association between G6PD genetic mutations and enzyme level was examined. Malaria parasitaemia and demographic features in the G6PD deficient and non-deficient individuals were characterized.

\section{Methods}

\section{Study site and sample collection}

A total of 344 blood samples were collected in seven study sites including Bure and Mankush from the north, Metehara and Shewa Robit from the east, as well as Halaba, Agaro, and Jimma from the southwest part of Ethiopia during 2013 to 2016 (Fig. 1). These study sites have high elevations, ranging from $1680 \mathrm{~m}$ to $2010 \mathrm{~m}$ above sea level. Malaria transmission is seasonal and unstable, with frequent epidemics in these areas. In Bure, Mankush, Metehara, Shewa Robit and Halaba, blood samples from 160 febrile patients visiting the health centers or hospitals were collected and these samples were included in G6PD genotyping. In Agaro and Jimma, blood samples from 184 febrile patients were collected and these samples were included in both G6PD genotyping and phenotyping assays. Genomic DNA was 


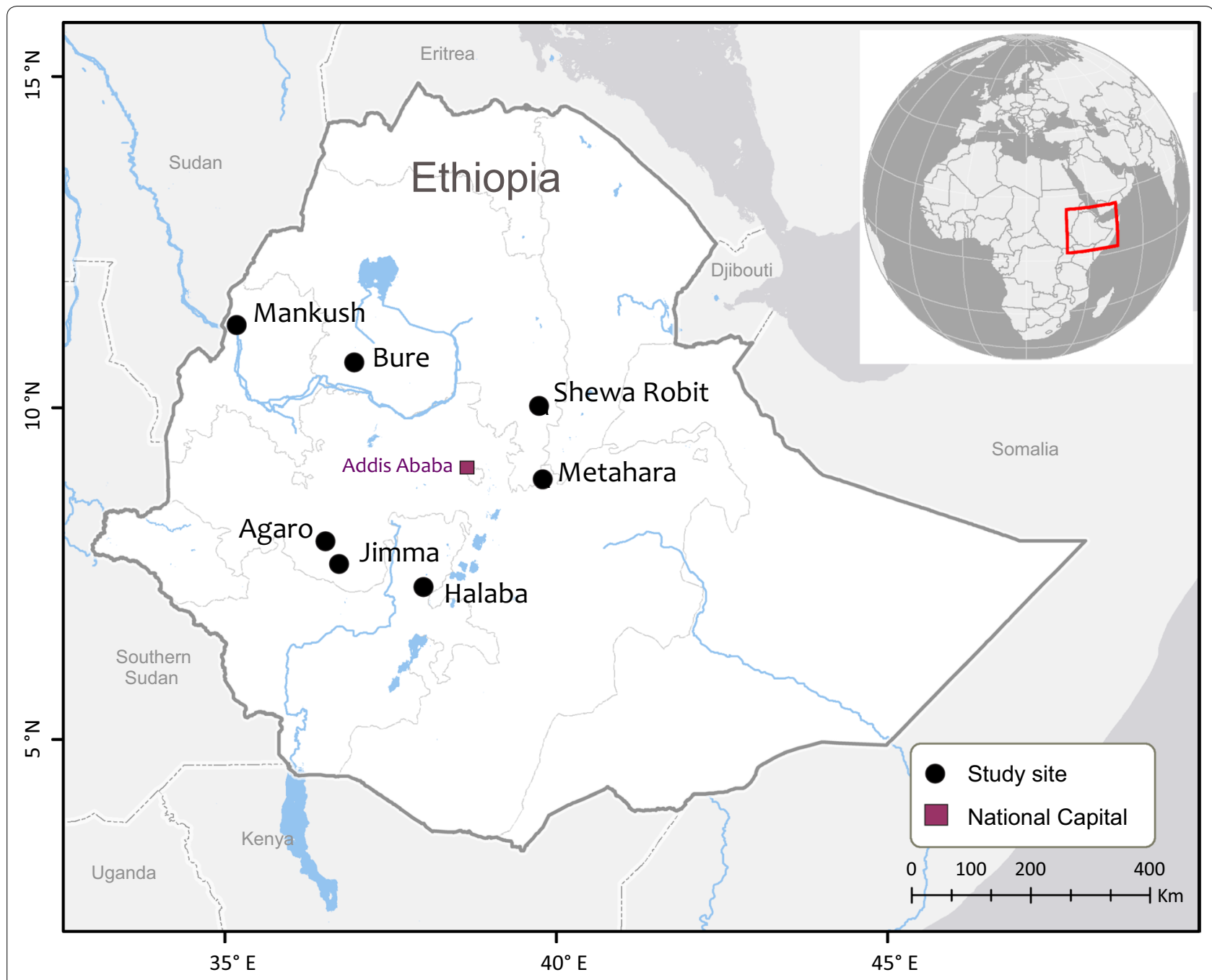

Fig. 1 Map showing the distribution of the seven study sites in Ethiopia

extracted from dried blood spots by the Saponin/Chelex method [31] and eluted in a total volume of $200 \mu \mathrm{l}$ TrisEDTA (TE) buffer.

\section{Molecular genotyping and G6PD gene sequencing}

For G6PD genotyping, four PCR assays were conducted to determine the G6PD gene mutations of exon 3-11 (Table 1). For each PCR assay, water was used in a separate reaction as a negative control. PCR amplification was conducted in a $20 \mu \mathrm{l}$ reaction mixture containing $2 \mu \mathrm{l}$ of genomic DNA $(\sim 50 \mathrm{ng} / \mu \mathrm{l}), 10 \mu \mathrm{l}$ of $2 \times$ Maxima SYBR Green qPCR Master Mix (Thermo Fisher) and 0.3 $\mathrm{uM}$ of each forward and reverse primers. Amplifications were performed with an initial denaturation at $94{ }^{\circ} \mathrm{C}$ for 3 min, followed by 38 cycles at $94{ }^{\circ} \mathrm{C}$ for $30 \mathrm{~s}, 55^{\circ} \mathrm{C}$ for $30 \mathrm{~s}$ and $72{ }^{\circ} \mathrm{C}$ for $60 \mathrm{~s}$, with a final 6 min extension at $72{ }^{\circ} \mathrm{C}$. Amplified PCR products were purified with 2
U Exonuclease I and 2U Shrimp Alkaline Phosphatase (Thermo Fisher) at $37{ }^{\circ} \mathrm{C}$ followed by 15 min incubation at $80{ }^{\circ} \mathrm{C}$ to deactivate the enzymes. Purified PCR products were sequenced in both directions on an ABI 3730xl DNA analyzer (Genewiz Inc., La Jolla, CA). Sequences were analysed using Codon Code Aligner Program version 7.0.1 (CodonCode Corporation, Centerville, MA). All sequences were aligned to the NCBI reference sequence (NG_009015.2) to verify the specificity of the PCR products. Samples with poor sequencing quality or showed singleton mutations were re-amplified and sequenced.

\section{G6PD phenotype measurement}

G6PD enzyme level was measured by CareStart $^{\mathrm{TM}}$ Biosensor (Access Bio, Seoul, Korea) on 400 clinical samples collected from Agaro and Jimma, Ethiopia 
Table 1 PCR primer sequences and amplicon size of G6PD gene

\begin{tabular}{|c|c|c|c|c|c|c|}
\hline PCR pair & Primer name & Primer sequence $\left(5^{\prime}-3^{\prime}\right)$ & Primer position & $\begin{array}{l}\text { PCR product } \\
\text { (bp) }\end{array}$ & $\begin{array}{l}\text { Coding region } \\
\text { (bp) }\end{array}$ & Exon coverage \\
\hline \multirow[t]{2}{*}{1} & $6284 \mathrm{~F}$ & CAAGGAGTGATTTGGGCAAT & 6284 & & & \\
\hline & $6755 R$ & AGAGCAAAACTCCGTCTCCA & 6755 & 472 & 120 & Exon 3 \\
\hline \multirow[t]{2}{*}{2} & D-6F & AATCTCGGGGCTCTTCTGTCTG & 16,237 & & & \\
\hline & D-1170R & GCAACGGCAAGCCTTACATCTG & 17,422 & 1185 & 365 & Exon 4-6 \\
\hline \multirow[t]{2}{*}{3} & D-1880F & CTTCGGGAGGGACCTGCAGAG & 18,107 & & & \\
\hline & $D-2865 R$ & GTGGTGACTTCTCCGGGGTTGA & 19,114 & 1007 & 379 & Exon 7-9 \\
\hline \multirow[t]{2}{*}{4} & G6-5F & CCTGAGGGCTGCACATCT & 19,356 & & & \\
\hline & G6-5R & GTGTCTTGCTGATGCCACTG & 20,096 & 740 & 423 & Exon 10-11 \\
\hline
\end{tabular}

Primer position can be referred to NCBI accession no. NG_009015.2

following the manufacturer's instruction. For each participant, demographic information was recorded by questionnaire. Briefly, for each sample, a G6PD test strip with two drops $(20-30 \mu \mathrm{l})$ of finger-prick whole blood was inserted into the biosensor at room temperature. The biosensor took about 4-5 min to indicate the G6PD reading and was automatically recorded. The G6PD enzyme activity was expressed in U/dl unit. A blank control was used to calibrate the G6PD biosensor to ensure the reading was zero before the next sample measurement. For each sample that was measured for G6PD enzyme level, haemoglobin level was also estimated using HemoCueHb 201+analyzer following the manufacturer's instruction. G6PD enzyme level was normalized by the concentration of haemoglobin (i.e. unit of G6PD enzyme per gram of haemoglobin, $\mathrm{U} / \mathrm{gHb}$ ). G6PD normal and deficient individuals were categorized into two class in male and three classes in female following the WHO classification $[11,32]$. The adjusted male median (AMM) G6PD activity, defined as the median G6PD activity of all male participants after excluding samples with less than $10 \%$ of the overall median activity, was calculated. For male, class I is G6PD deficient with $<30 \%$ of the AMM activity and class II is normal with $>30 \%$ of the AMM activity. For female, G6PD activity $<30 \%, 30-80 \%$, and $>80 \%$ of the AMM activity are considered as G6PD deficient, intermediate, and normal, respectively [32].

\section{Data analysis}

All statistical analyses were performed using JMP Pro 12.2.0 software (SAS Institute Inc. 2015). The MannWhitney U test was used for non-parametric comparisons, and Student's t test and one-way analysis of variance for parametric comparisons. Fisher's exact test was used to examine the association between G6PD genotype and phenotype at the confidence level of $P=0.05$.

\section{Results}

\section{Frequency of G6PD gene mutations}

A total of 344 febrile patients collected from seven study sites in Ethiopia were sequenced for the G6PD exons 3-11. The common mutation A376G (rs1050829, A $\rightarrow$ G) was detected in $21(6.1 \%)$ of the individuals, of which ten were homozygote for G376 and eight were heterozygotes (Table 2). This mutation was found in all study sites except Shewa Robit (East Ethiopia). Other mutations including G267+119C/T (rs782000110, C $\rightarrow \mathrm{T}$ ) and G1116A (rs2230036, G $\rightarrow$ A) were detected in 4 $(1.2 \%)$ and $4(1.2 \%)$ individuals, respectively (Table 2 ). The G267+119C/T (rs782000110, C $\rightarrow$ T) mutation was found exclusively in Agaro and Jimma (South Ethiopia); whereas the G1116A ( $r 2230036, \mathrm{G} \rightarrow \mathrm{A}$ ) mutation was found in both East and South Ethiopia. The absence of these mutations in the north could be due to small sample size $(N=48$; Table 2). All these three mutations were found separately in different individuals. For other previously reported positions [30] such as G202A at exon 4, chrX:154535443 C-T at exon 5, and C563T at exon 6, no mutations were detected among the samples (Table 2). It is noted that the G6PD sequences presented in this study did not cover the two intronic positions (rs370658483, $485+37 \mathrm{G} \rightarrow \mathrm{T}$ and $\mathrm{rs} 782669677,535 \mathrm{G} \rightarrow \mathrm{A}$ ) that were previously shown to be polymorphic but rare among the Ethiopians [30].

Among the 344 febrile patients, a subset of 184 individuals from Agaro and Jimma (South Ethiopia) were analysed further by demography and malaria infection. For the three positions A376G, G267 + 119C-T, and G1116A where mutations were observed, the mutation frequency ranged from 0.9 to $5.1 \%$ in males and 2.3 to $5.6 \%$ in females. No significant difference was observed in the mutation frequency between males and females (onetailed $t$ test, $P=0.47$; Table 3 ). As expected, only hemizygotes (i.e., individuals with only one allele of the G6PD gene) were observed in the male patients, whereas both 


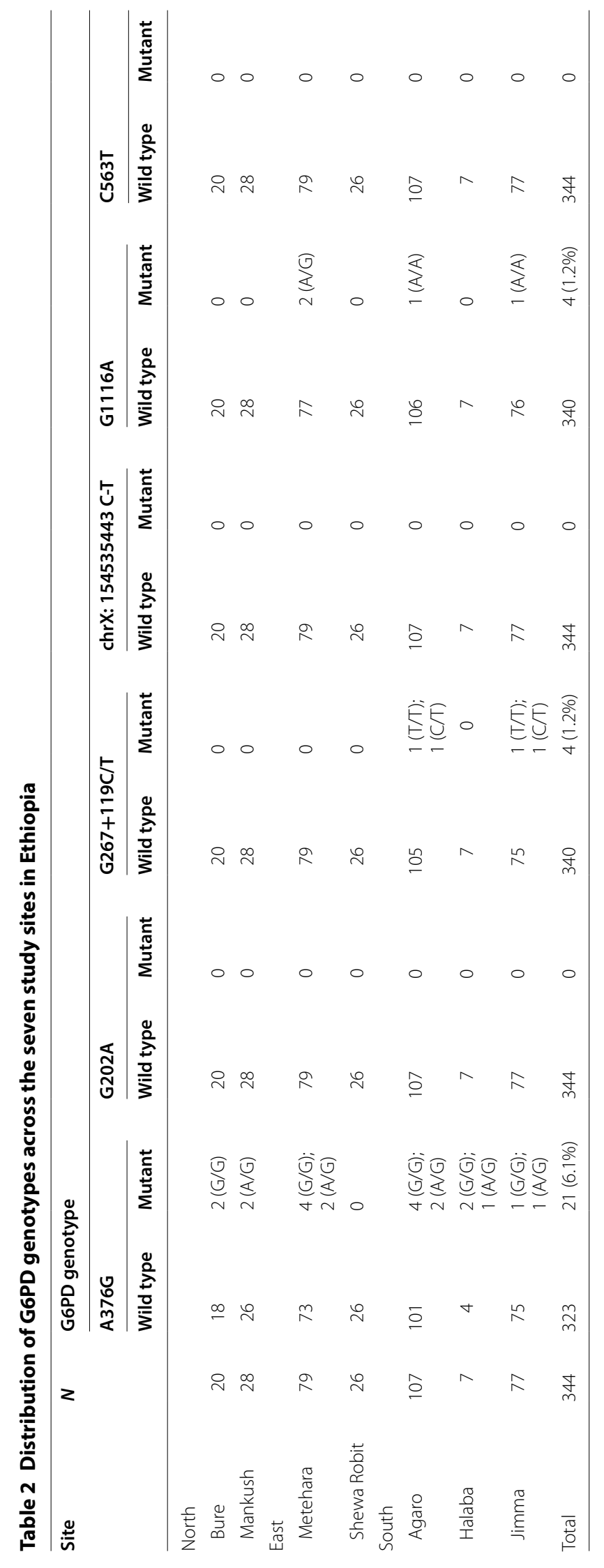


Table 3 Distribution of three G6PD genotypes where mutations were detected among male and female individuals in Jimma and Agaro, southwestern Ethiopia

\begin{tabular}{|c|c|c|c|c|c|c|c|}
\hline \multirow[t]{3}{*}{ Gender } & \multirow[t]{3}{*}{$N$} & \multicolumn{6}{|c|}{ G6PD genotype } \\
\hline & & \multicolumn{2}{|l|}{ A376G } & \multicolumn{2}{|c|}{ G267+119C/T } & \multicolumn{2}{|l|}{ G1116A } \\
\hline & & Wild type & Mutant & Wild type & Mutant & Wild type & Mutant \\
\hline Male & 118 & $\begin{array}{l}112 \\
(94.9 \%)\end{array}$ & $\begin{array}{l}6(\mathrm{G} / \mathrm{G}) \\
(5.1 \%)\end{array}$ & $\begin{array}{l}117 \\
(99.1 \%)\end{array}$ & $\begin{array}{l}1(\mathrm{~T} / \mathrm{T}) \\
(0.9 \%)\end{array}$ & $\begin{array}{l}116 \\
(98.3 \%)\end{array}$ & $\begin{array}{l}2(\mathrm{~A} / \mathrm{A}) \\
(1.7 \%)\end{array}$ \\
\hline Female & 89 & $\begin{array}{l}84 \\
(94.4 \%)\end{array}$ & $\begin{array}{l}2(\mathrm{G} / \mathrm{G}) ; 3(\mathrm{~A} / \mathrm{G}) \\
(5.6 \%)\end{array}$ & $\begin{array}{l}87 \\
(97.7 \%)\end{array}$ & $\begin{array}{l}1(\mathrm{~T} / \mathrm{T}) ; 1(\mathrm{C} / \mathrm{T}) \\
(2.3 \%)\end{array}$ & $\begin{array}{l}89 \\
(100 \%)\end{array}$ & 0 \\
\hline
\end{tabular}

Due to the lack of demographic information, samples from other study sites were not included in this analysis

heterozygotes and homozygote recessive were observed in the female patients.

Among the 344 febrile patients, 158 (45.9\%) were diagnosed with malaria. Of these 158 malaria patients, the mutation frequency of the three G6PD gene positions (A376G, G267 + 119C-T, and G1116A) ranged from 0.6 to $4.4 \%$ (Table 4). Between the malaria-infected and noninfected patients, we found no significant difference in the mutation frequency for A376G, G267 + 119C-T and G1116A (one-tailed t-test, $P=0.15$; Table 4). Likewise, no significant difference was observed in the mutation frequency when the samples were stratified by age, i.e., under 5, 5-15 and above 14 years old, despite a marked difference in sample size among the three age groups (Additional file 1: Table S1).

\section{Measurement of G6PD enzyme activity}

Based on the WHO guidelines [11, 32], the AMM G6PD activity of all male participants after excluding samples with less than $10 \%$ of the overall median activity was 6.25 $\mathrm{U} / \mathrm{gHb}$. Thus, patients with value $<1.88 \mathrm{U} / \mathrm{gHb}$ (i.e., $<30 \%$ of the AMM activity) were considered as G6PD deficient in both male and female. Among the 400 patients from Agaro and Jimma (southwestern Ethiopia), 17 (4.3\%) had G6PD activity $<1.88 \mathrm{U} / \mathrm{gHb}$ and were considered as G6PD deficient. One of these 17 patients was under the age of 5, one was aged 5-14, and the remaining were above the age of 14 (Fig. 2a). No significant difference was observed in the distribution of G6PD level among the three age groups despite the remarkable difference in sample size (Fig. 2a).

Likewise, no significant difference was observed in the distribution of G6PD enzyme level between males and females (average G6PD level $=6.3 \pm 2.5 \mathrm{U} / \mathrm{gHb}$ for both gender; one-tailed t-test, $P=0.56$; Fig. $2 \mathrm{~b}$ ). For male, G6PD level ranged from 0.62 to $20.16 \mathrm{U} / \mathrm{gHb}$, and 10 out of $184(5.4 \%)$ were G6PD deficient. For female, G6PD level ranged from 0.76 to $13.86 \mathrm{U} / \mathrm{gHb} ; 7$ out of 136 (5.2\%) were G6PD deficient, 47 (34.6\%) were G6PD intermediate, and 82 (60.3\%) were G6PD normal (Fig. 2b). The prevalence of low G6PD was not significantly different between the two groups.

Of the 158 patient samples (95 males and 63 females) that were diagnosed with malaria, $11(6.9 \%)$ were considered as G6PD deficient (Fig. 3). For the non-infected individuals, 5 out of $49(8.2 \%)$ were considered as G6PD deficient. Despite the contrast in sample size, there was no significant difference in the distribution of G6PD level between these two groups of individuals (one-tailed t-test, $P=0.05$; Fig. 3). Among the malaria-infected patients, no significant difference was detected in the microscopic-based parasitaemia between the low and normal G6PD individuals (one-tailed t-test, $P=0.06$; Fig. 4). Two of the 158 malaria patients were diagnosed with $P$. falciparum, whereas the rest with $P$. vivax infections. The two $P$. falciparum-infected patients had a G6PD level of 4.87 and $5.20 \mathrm{U} / \mathrm{gHb}$, respectively, and were considered as G6PD normal.

Table 4 Distribution of G6PD genotypes among non-infected and malaria-infected individuals in Ethiopia

\begin{tabular}{|c|c|c|c|c|c|c|c|}
\hline \multirow[t]{3}{*}{ Type of patients } & \multirow[t]{3}{*}{$N$} & \multicolumn{6}{|c|}{ G6PD genotype } \\
\hline & & \multicolumn{2}{|l|}{ A376G } & \multicolumn{2}{|c|}{$\mathrm{G} 267+119 \mathrm{C} / \mathrm{T}$} & \multicolumn{2}{|l|}{ G1116A } \\
\hline & & Wild type & Mutant & Wild type & Mutant & Wild type & Mutant \\
\hline Non-malaria & 49 & $\begin{array}{l}45 \\
(91.8 \%)\end{array}$ & $\begin{array}{l}2(\mathrm{G} / \mathrm{G}) ; 2(\mathrm{~A} / \mathrm{G}) \\
(8.2 \%)\end{array}$ & $\begin{array}{l}48 \\
(97.9 \%)\end{array}$ & $\begin{array}{l}1(\mathrm{C} / \mathrm{T}) \\
(2.1 \%)\end{array}$ & $\begin{array}{l}49 \\
(100 \%)\end{array}$ & 0 \\
\hline Malaria-infected & 158 & $\begin{array}{l}151 \\
(95.6 \%)\end{array}$ & $\begin{array}{l}6(\mathrm{G} / \mathrm{G}) ; 1(\mathrm{~A} / \mathrm{G}) \\
(4.4 \%)\end{array}$ & $\begin{array}{l}157 \\
(99.4 \%)\end{array}$ & $\begin{array}{l}2(\mathrm{~T} / \mathrm{T}) \\
(0.6 \%)\end{array}$ & $\begin{array}{l}157 \\
(99.4 \%)\end{array}$ & $\begin{array}{l}2(\mathrm{~A} / \mathrm{A}) \\
(0.6 \%)\end{array}$ \\
\hline
\end{tabular}



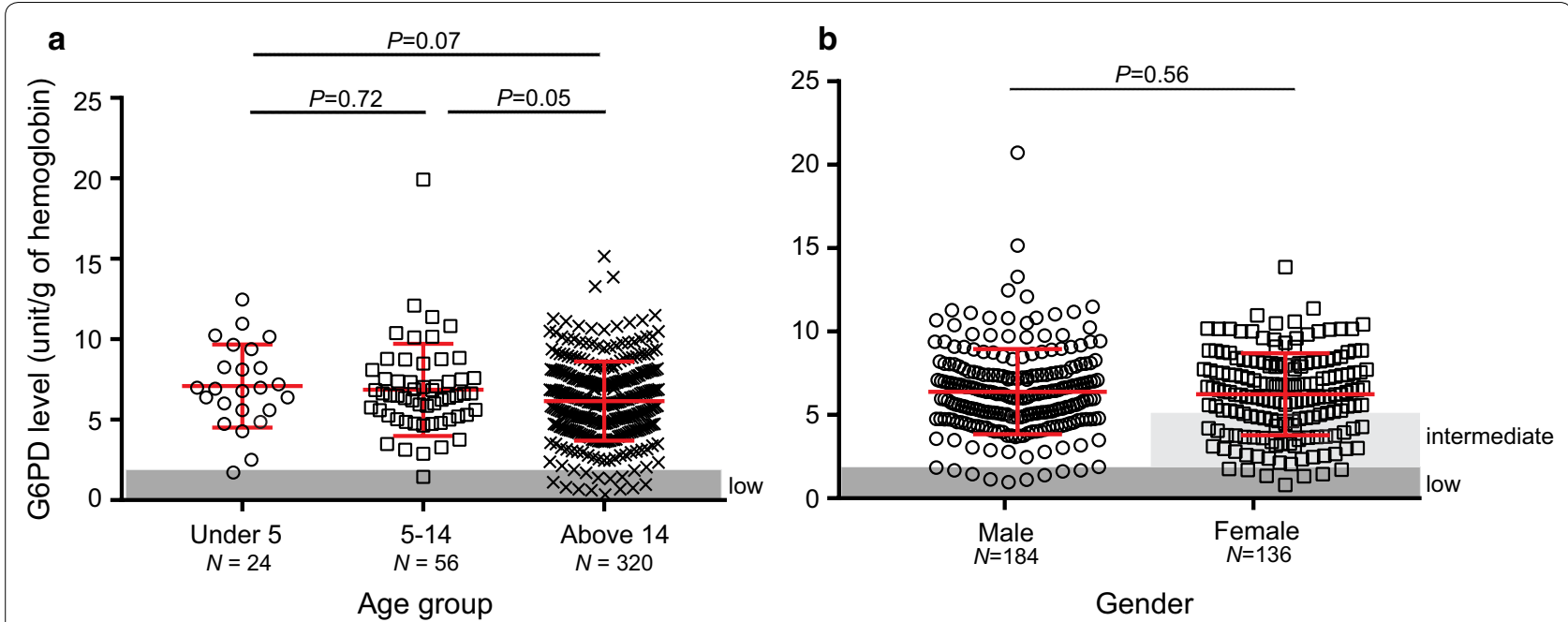

Fig. 2 Comparison of G6PD level a among three age groups (under 5, 5-14 and above 14 years old) and $\mathbf{b}$ between males and females. Area in gray indicates samples with G6PD level below 1.88 unit/g of hemoglobin and were considered as deficient. No significant difference was observed in the G6PD level

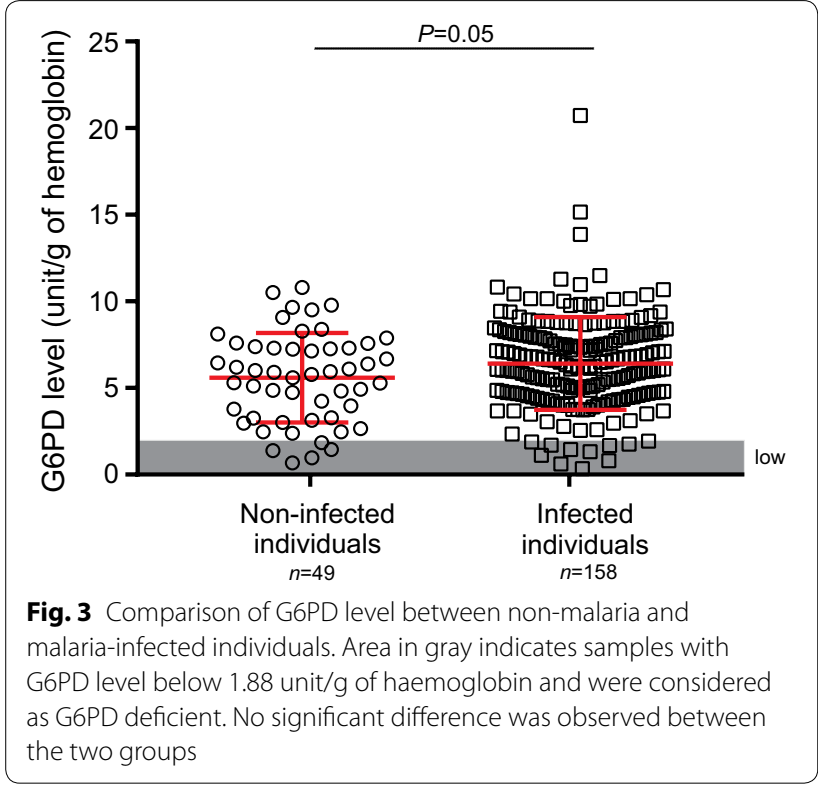

\section{Association between genotype and phenotype}

The G6PD genotype was compared with phenotype for a subset of 184 samples collected from Agaro and Jimma (Table 2). The G6PD enzyme level was compared among the different genotypes (Fig. 5). Of the 174 samples that were indicated with no G6PD mutations, one sample had a G6PD level of $1.69 \mathrm{U} / \mathrm{gHb}$ and was considered as G6PD deficient (Fig. 5). For the six samples that had mutation A376G (G/G and A/G), G6PD level ranged from 5.38 to $9.77 \mathrm{U} / \mathrm{gHb}$ and all were considered as G6PD normal. For the two samples with mutation G267 + 119C-T (T/T

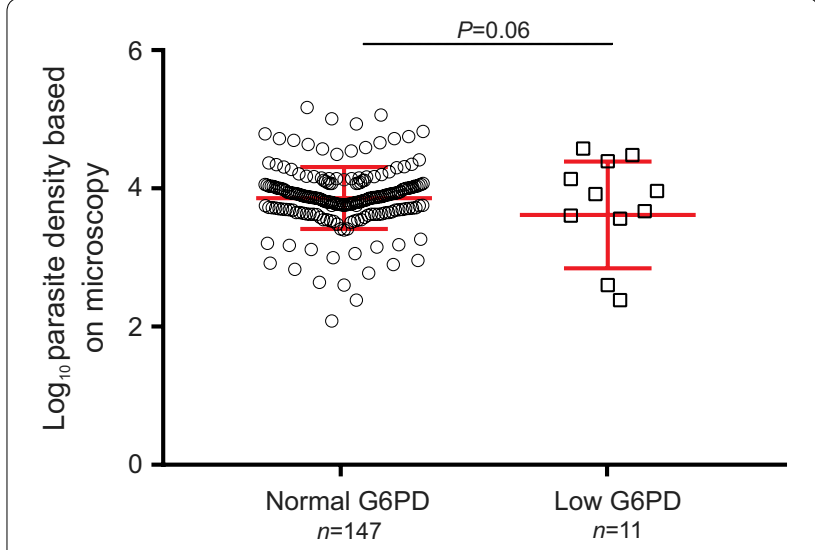

Fig. 4 Comparison of microscopic-based parasitaemia between individuals with normal and low G6PD level

and $\mathrm{C} / \mathrm{T}$ ), G6PD level was normal (5.62 and $10.17 \mathrm{U} / \mathrm{gHb}$, respectively). Likewise, the two samples with mutation G1116A (A/A) also had normal G6PD level (6.61 and $9.17 \mathrm{U} / \mathrm{gHb}$, respectively; Fig. 5). Thus, the mutations observed in A376G, G267 + 119C-T, and G1116A did not associate with low G6PD, despite the limited number of samples in the present study.

\section{Discussion}

To date, 8-aminoquinolines, primaquine and tafenoquine are the only effective drugs that eradicate the dormant liver stages of $P$. vivax and avoid relapse. However, primaquine and tafenoquine can cause acute haemolytic anaemia in individuals with low G6PD enzyme level. 


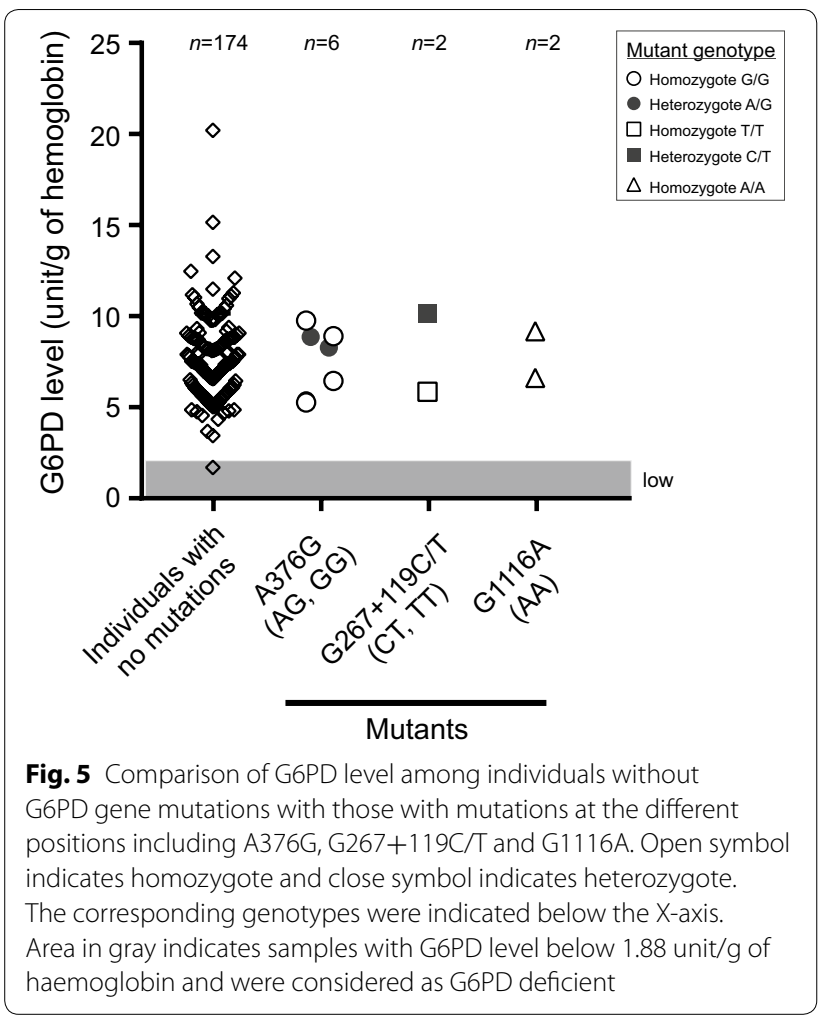

The issue of low G6PD has also impacted the use of primaquine as gametocytocide for $P$. falciparum malaria. In the Greater Mekong Subregion, G6PD deficiency has been reported to be common in males with a prevalence of $7.3 \%$ to $18.8 \%$ based on the CareStart ${ }^{\mathrm{TM}}$ Fluorescent Spot Test [33]. In Bangladesh, a prevalence of $17.4 \%$ $(173 / 995)$ for G6PD deficiency $(<60 \%$ of the adjusted male median G6PD activity) was reported using standard UV spectrophotometry [34]. Using the CareStart ${ }^{\mathrm{TM}}$ G6PD test kit, this study identified a prevalence of 4.3\% G6PD deficiency among febrile patients in southwestern Ethiopia based on a threshold cutoff of $1.88 \mathrm{U} / \mathrm{g} \mathrm{Hb}$ (i.e. $<30 \%$ of the AMM G6PD activity). This prevalence rate was slightly higher than a previous report of 1.4\% G6PD deficiency in other parts of Ethiopia using the same device and cutoff threshold [35], but much lower than those reported in Asia [33, 34]. Such a pattern indicated differences not only at the continental but also regional level in the distribution of G6PD deficiency.

Some earlier studies demonstrated an association of low G6PD level with a low risk of asymptomatic $P$. falciparum infections [36]; whereas others showed no association of G6PD deficiency with total severe malaria or diseases caused by malaria parasite species [37]. While the potential association between low G6PD level and host immunity is not tested in the present study because of sampling bias towards malaria patients, malaria-infected individuals with normal G6PD enzyme level indicated a slightly but non-significantly higher parasite density than those with low G6PD enzyme. Association analyses did not reveal a significance difference in G6PD enzyme level between males and females, as well as among various age groups. While most of the populations in southwestern Ethiopia belong to either the Amhara or Oromo tribes, ethnicity data of the included patients is not available for us to formally test the association between ethnicity and G6PD enzyme level.

More than 400 allelic variants of the G6PD gene have been reported [10, 18, 26, 38, 39]. Among the 344 Ethiopian samples, three SNPs were detected between exon 3 and exon 11 of the G6PD gene, including codon A376G, one of the most common G6PD mutations with an average frequency of $6.1 \%$ across the study sites. This mutation has also been previously reported in in Ethiopia $[30,35,40]$. The other two mutations G267+119C/T and G116A were detected with relatively low frequencies in this study. Based on the analyses of a subset of 184 samples, none of these mutations was associated with low G6PD enzyme level. One possible explanation could be only a small number of low G6PD samples were sequenced. The association between G6PD genotype and phenotype merits further verification with broader samples. Another possibility is that there could be other codons of the G6PD gene that we did not sequence in this study. Also, G6PD phenotype was only measured by one but not multiple biosensors or device for comparison. The CareStart ${ }^{\mathrm{TM}}$ G6PD rapid test kit used in this study has the advantages of being small and handy, easy to perform, produce results within a few minutes, and can be used without electricity or specific equipment. It is affordable and can detect G6PD enzyme activity at a very low level [41]. Compared with the gold standard photospectrometric assay, the sensitivity and specificity of the CareStart ${ }^{\mathrm{TM}}$ test kit are $90-100 \%$ and $84.8-100 \%$, respectively [33, 41, 42], although a low sensitivity was also reported when used on individuals with G6PD enzyme activity $<30 \%[43$, 44]. Though this CareStart ${ }^{\mathrm{TM}}$ G6PD test kit represents a significant improvement for quantitative diagnosis of G6PD level over previous models, the accuracy of its measurement still requires further validation before clinical deployment. It is also noteworthy that the samples included in the present study were febrile patients instead of the general population, and that such sampling could bias with a high number of malaria-infected individuals. Thus, this study is limited to inferring the distribution of G6PD level between non-malaria and malaria-infected samples rather than the rate of malaria infection between normal and low G6PD individuals. 


\section{Conclusion}

Based on G6PD genotyping, the present study revealed a modest prevalence of G6PD deficiency among febrile patients across Ethiopia. A routine testing for G6PD deficiency prior to administrating primaquine for radical cure of $P$. vivax infected patients is recommend in Ethiopia and other Africa countries. G6PD genotype was not significantly associated with G6PD phenotype. Nevertheless, this association merits further testing with broader samples. Future study should also compare G6PD measurement among different devices with the CareStart ${ }^{\mathrm{TM}}$ biosensor to validate accuracy before clinical deployment in Ethiopia as well as other malarious countries.

\section{Supplementary information}

Supplementary information accompanies this paper at https://doi. org/10.1186/s12936-019-2981-x.

Additional file 1: Table S1. Distribution of G6PD genotypes among different age groups. $P>0.05$ for all pairwise comparison, indicative of no significant difference in mutation frequency among the three age groups.

\section{Abbreviations}

G6PD: glucose-6-phosphate dehydrogenase; CQ: chloroquine; AMM: adjusted male median; ACT: Artemisinin Combination Therapy.

\section{Acknowledgements}

We are greatly indebted to technicians and the staffs from Jimma University Tropical and Infectious Diseases Research Center (TIDRC) for sample collection and preliminary laboratory work; the communities and hospitals for their support and willingness to participate in this research; and undergraduate students Sylvia Akar and Chelsea Dy from University of California Irvine for assisting data collection

\section{Authors' contributions}

EL, DZ, DY and GY conceived and designed the study; EL, DZ, BR, and MCL collected the samples; EL, DZ, DY, BR, KP, and CK collected and analysed the data; EL, DZ and KP wrote the paper. All authors read and approved the final manuscript.

\section{Funding}

The work was supported by Grants from the National Institutes of Health (R15 Al138002, R01 Al050243, U19 Al129326, and D43 TW001505).

\section{Availability of data and materials}

All data generated or analysed in this study are included in this published article and its Additional file 1.

\section{Ethics approval and consent to participate}

Ethical approval for this study was granted by the Institutional Scientific and Ethical Review Boards of Institute of Health, Jimma University, Ethiopia and University of California, Irvine, USA. Written informed consent/assent was obtained from all consenting heads of households, parents/guardians, and each individual who was willing to participate in the study. All experimental procedures were performed following the IRB approved protocol.

\section{Competing interests}

The authors declare that they have no competing interests.

\section{Consent for publication}

Not applicable.

\section{Author details}

1 Biological Sciences, University of North Carolina at Charlotte, Charlotte, NC 28223, USA. ${ }^{2}$ Program in Public Health, College of Health Sciences, University of California, Irvine, CA 92697, USA. ${ }^{3}$ School of Medical Laboratory Sciences, Jimma University, Jimma, Ethiopia. ${ }^{4}$ Eck Institute for Global Health, University of Notre Dame, Notre Dame, IN 46556, USA. ${ }^{5}$ Tropical and Infectious Diseases Research Center, Jimma University, Jimma, Ethiopia.

Received: 18 June 2019 Accepted: 28 September 2019

Published online: 07 October 2019

\section{References}

1. Nkhoma ET, Poole C, Vannappagari V, Hall SA, Beutler E. The global prevalence of glucose-6-phosphate dehydrogenase deficiency: a systematic review and meta-analysis. Blood Cells Mol Dis. 2009;42:267-78.

2. Tishkoff SA, Varkonyi R, Cahinhinan N, Abbes S, Argyropoulos G, DestroBisol G, et al. Haplotype diversity and linkage disequilibrium at human G6PD: recent origin of alleles that confer malarial resistance. Science. 2001;293:455-62.

3. Luzzatto L. G6PD deficiency and malaria selection. Heredity (Edinb). 2012;108:456.

4. Sirugo G, Predazzi IM, Bartlett J, Tacconelli A, Walther M, Williams SM. G6PD A- deficiency and severe malaria in The Gambia: heterozygote advantage and possible homozygote disadvantage. Am J Trop Med Hyg. 2014;90:856-9.

5. Manjurano A, Sepulveda N, Nadjm B, Mtove G, Wangai H, Maxwell C, et al. African glucose-6-phosphate dehydrogenase alleles associated with protection from severe malaria in heterozygous females in Tanzania. PLoS Genet. 2015:11:e1004960.

6. Howes RE, Piel FB, Patil AP, Nyangiri OA, Gething PW, Dewi M, et al. G6PD deficiency prevalence and estimates of affected populations in malaria endemic countries: a geostatistical model-based map. PLoS Med. 2012:9:e1001339

7. WHO. Guidelines for the treatment of malaria. Geneva: World Health Organization; 2015

8. Recht J, Ashley EA, White NJ. Use of primaquine and glucose-6-phosphate dehydrogenase deficiency testing: divergent policies and practices in malaria endemic countries. PLoS Negl Trop Dis. 2018;12:e0006230.

9. Lee DH, Warkentin TE, Neame PB, Ali MA. Acute hemolytic anemia precipitated by myocardial infarction and pericardial tamponade in G6PD deficiency. Am J Hematol. 1996;51:174-5.

10. Drousiotou A, Touma EH, Andreou N, Loiselet J, Angastiniotis M, Verrelli BC, et al. Molecular characterization of G6PD deficiency in Cyprus. Blood Cells Mol Dis. 2004:33:25-30.

11. WHO. Testing for G6PD deficiency for safe use of primaquine in radical cure of P. vivax and P. ovale malaria. Geneva: World Health Organization; 2016. https://www.who.int/malaria/publications/atoz/g6pd-testing-pqradical-cure-vivax/en/.

12. WHO. Updated WHO Policy Recommendation (October 2012): Single dose Primaquine as a gametocytocide in Plasmodium falciparum malaria. Geneva: World Health Organization; 2012. https://www.who.int/malaria/ publications/atoz/who_pq_policy_recommendation/en/.

13. Domingo GJ, Satyagraha AW, Anvikar A, Baird K, Bancone G, Bansil P, et al. G6PD testing in support of treatment and elimination of malaria: recommendations for evaluation of G6PD tests. Malar J. 2013:12:391.

14. Fernando D, Rodrigo C, Rajapakse $S$. Primaquine in vivax malaria: an update and review on management issues. Malar J. 2011;10:351.

15. Pamba A, Richardson ND, Carter N, Duparc S, Premji Z, Tiono A, et al. Clinical spectrum and severity of hemolytic anemia in glucose 6-phosphate dehydrogenase-deficient children receiving dapsone. Blood. 2012;120:4123-33.

16. Mason PJ, Bautista JM, Gilsanz F. G6PD deficiency: the genotype-phenotype association. Blood Rev. 2007;21:267-83.

17. Cappellini MD, Fiorelli G. Glucose-6-phosphate dehydrogenase deficiency. Lancet. 2008;371:64-74.

18. Nantakomol D, Paul R, Palasuwan A, Day NP, White NJ, Imwong M. Evaluation of the phenotypic test and genetic analysis in the detection of the glucose-6-phosphate dehydrogenase deficiency. Malar J. 2013;12:289. 
19. WHO. Control and elimination of Plasmodium vivax malaria- a technical brief. Geneva: World Health Organization; 2015. https://www.who.int/ malaria/publications/atoz/9789241509244/en/.

20. Hill DR, Baird JK, Parise ME, Lewis LS, Ryan ET, Magill AJ. Primaquine: report from CDC expert meeting on malaria chemoprophylaxis. Am J Trop Med Hyg. 2006;75:402-15.

21. Gonzalez-Ceron L, Rodriguez MH, Sandoval MA, Santillan F, GalindoVirgen S, Betanzos AF, et al. Effectiveness of combined chloroquine and primaquine treatment in 14 days versus intermittent single dose regimen, in an open, non-randomized, clinical trial, to eliminate Plasmodium vivax in southern Mexico. Malar J. 2015;14:426.

22. Durand S, Cabezas C, Lescano AG, Galvez M, Gutierrez S, Arrospide N, et al. Efficacy of three different regimens of primaquine for the prevention of relapses of Plasmodium vivax malaria in the Amazon Basin of Peru. Am J Trop Med Hyg. 2014;91:18-26.

23. Martini G, Toniolo D, Vulliamy T, Luzzatto L, Dono R, Viglietto G, et al. Structural analysis of the $X$-linked gene encoding human glucose 6-phosphate dehydrogenase. EMBO J. 1986;5:1849-55.

24. Gomez-Manzo S, Terron-Hernandez J, de la Mora I, Garcia-Torres I, LopezVelazquez G, Reyes-Vivas H, et al. Cloning, expression, purification and characterization of his-tagged human glucose-6-phosphate dehydrogenase: a simplified method for protein yield. Protein J. 2013;32:585-92.

25. Doss CG, Alasmar DR, Bux DI, Sneha P, Bakhsh FD, Al-Azwani I, et al. Genetic epidemiology of glucose-6-phosphate dehydrogenase deficiency in the Arab World. Sci Rep. 2016;6:37284.

26. Sarker SK, Islam MT, Eckhoff G, Hossain MA, Qadri SK, Muraduzzaman AK, et al. Molecular analysis of glucose-6-phosphate dehydrogenase gene mutations in Bangladeshi Individuals. PLoS One. 2016;11:e0166977.

27. Beutler E. G6PD deficiency. Blood. 1994;84:3613-36.

28. Lo E, Yewhalaw D, Zhong D, Zemene E, Degefa T, Tushune K, et al. Molecular epidemiology of Plasmodium vivax and Plasmodium falciparum malaria among Duffy-positive and Duffy-negative populations in Ethiopia. Malar J. 2015;14:84.

29. Tsegaye A, Golassa L, Mamo H, Erko B. Glucose-6-phosphate dehydrogenase deficiency among malaria suspects attending Gambella hospital, southwest Ethiopia. Malar J. 2014;13:438.

30. Carter TE, Mekonnen SK, Lopez K, Bonnell V, Damodaran L, Aseffa A, et al. Glucose-6-phosphate dehydrogenase deficiency genetic variants in malaria patients in Southwestern Ethiopia. Am J Trop Med Hyg. 2018:98:83-7.

31. Bereczky S, Martensson A, Gil JP, Farnert A. Rapid DNA extraction from archive blood spots on filter paper for genotyping of Plasmodium falciparum. Am J Trop Med Hyg. 2005;72:249-51.

32. WHO. In vitro diagnostics medical devices to identify Glucose-6-phosphate dehydrogenase (G6PD)'activity. Geneva: World Health Organization; 2016. https://apps.who.int/iris/handle/10665/252628. Accessed 25 Apr 2019.
33. Bancone G, Menard D, Khim N, Kim S, Canier L, et al. Molecular characterization and mapping of glucose-6-phosphate dehydrogenase (G6PD) mutations in the Greater Mekong Subregion. Malar J. 2019;18:20.

34. Ley B, Alam MS, O’Donnell JJ, Hossain MS, Kibria MG, Jahan N, et al. A comparison of three quantitative methods to estimate G6PD activity in the Chittagong Hill Tracts, Bangladesh. PLoS One. 2017;12:e0169930.

35. Shitaye G, Gadisa E, Grignard L, Shumie G, Chali W, Menberu T, et al. Low and heterogeneous prevalence of glucose-6-phosphate dehydrogenase deficiency in different settings in Ethiopia using phenotyping and genotyping approaches. Malar J. 2018;17:281.

36. Amoah LE, Opong A, Ayanful-Torgby R, Abankwa J, Acquah FK. Prevalence of G6PD deficiency and Plasmodium falciparum parasites in asymptomatic school children living in southern Ghana. Malar J. 2016;15:388.

37. Mbanefo EC, Ahmed AM, Titouna A, Elmaraezy A, Trang NT, Phuoc Long N, et al. Association of glucose-6-phosphate dehydrogenase deficiency and malaria: a systematic review and meta-analysis. Sci Rep. 2017;7:45963.

38. Louicharoen C, Nuchprayoon I. G6PD Viangchan $(871 \mathrm{G}>\mathrm{A})$ is the most common G6PD-deficient variant in the Cambodian population. J Hum Genet. 2005;50:448-52.

39. Chen Y, Xiu W, Dong Y, Wang J, Zhao H, Su Y, et al. Mutation of glucose6-phosphate dehydrogenase deficiency in Chinese Han children in eastern Fujian. Medicine (Baltimore). 2018;97:e11553.

40. Assefa A, Ali A, Deressa W, Tsegaye W, Abebe G, Sime H, et al. Glucose6-phosphate dehydrogenase (G6PD) deficiency in Ethiopia: absence of common African and Mediterranean allelic variants in a nationwide study. Malar J. 2018;17:388.

41. von Fricken ME, Weppelmann TA, Eaton WT, Masse R, Rochars MV, Okech BA. Performance of the CareStart ${ }^{\mathrm{TM}}$ glucose-6-phosphate dehydrogenase (G6PD) rapid diagnostic test in Gressier, Haiti. Am J Trop Med Hyg. 2014:91:77-80.

42. Adu-Gyasi D, Asante KP, Newton S, Dosoo D, Amoako S, Adjei G, et al. Evaluation of the diagnostic accuracy of CareStart ${ }^{\mathrm{TM}}$ G6PD deficiency Rapid Diagnostic Test (RDT) in a malaria endemic area in Ghana, Africa. PLoS One. 2015;10:e0125796.

43. Kim S, Nguon C, Guillard B, Duong S, Chy S, Sum S, et al. Performance of the CareStart ${ }^{\mathrm{TM}}$ G6PD deficiency screening test, a point-of-care diagnostic for primaquine therapy screening. PLoS One. 2011;6:e28357.

44. Monteiro WM, Brito MAM, Lacerda MVG. Accuracy of CareStart ${ }^{\mathrm{TM}}$ G6PD rapid diagnostic test: variation in results from different commercial versions. Rev Soc Bras Med Trop. 2017;50:282-3.

\section{Publisher's Note}

Springer Nature remains neutral with regard to jurisdictional claims in published maps and institutional affiliations.
Ready to submit your research? Choose BMC and benefit from:

- fast, convenient online submission

- thorough peer review by experienced researchers in your field

- rapid publication on acceptance

- support for research data, including large and complex data types

- gold Open Access which fosters wider collaboration and increased citations

- maximum visibility for your research: over $100 \mathrm{M}$ website views per year

At BMC, research is always in progress.

Learn more biomedcentral.com/submissions 